\title{
Entre a servidão e a beira-mar: um estudo configuracional da segregação socioespacial na Área Conurbada de Florianópolis (ACF), Brasil
}

\section{A configurational study of sociospatial segregation in Florianopolis' Conurbation} Area (ACF), Brazil

Bruna da Cunha Kronenberger[a] $\mathbb{C}$, Renato Tibiriçá de Saboya[a]

[a] Universidade Federal de Santa Catarina (UFSC), Departamento de Arquitetura e Urbanismo, Florianópolis, SC, Brasil

Como citar: Kronenberger, B. C., \& Saboya, R. T. (2019). Entre a servidão e a beira-mar: um estudo configuracional da segregação socioespacial na Área Conurbada de Florianópolis (ACF), Brasil. urbe. Revista Brasileira de Gestão Urbana, 11, e20170227. https://doi.org/10.1590/2175-3369.011.e20170227

\section{Resumo}

Neste artigo, examinaram-se as relações entre a desigualdade socioeconômica e a localização entre as diferentes classes socioeconômicas da Área Conurbada de Florianópolis (ACF). Construiu-se um índice socioeconômico a partir dos dados da Pesquisa Universo do Censo do IBGE 2010 e o comparou com as propriedades configuracionais usando a Teoria da Sintaxe Espacial e suas principais medidas. Diversas recorrências foram identificadas, tanto em âmbito local quanto global. Os resultados mostram que grupos mais privilegiados socioeconomicamente tendem a ocupar áreas altamente acessíveis. Apesar de médias mais altas de Escolha Global, verificou-se que camadas mais altas tendem a evitar localizações diretas em ruas principais ou rodovias, preferindo localizações mais reservadas, o que parece expressar uma estratégia de equilíbrio entre um relativo isolamento e um fácil acesso ao centro. Por outro lado, faixas com piores condições socioeconômicas estão mais frequentemente localizadas ao longo dessas vias, pelo menos quando possuem características de rodovias. Em âmbito local, as descontinuidades do tecido urbano e a prevenção da visibilidade mútua são as estratégias utilizadas para separar duas áreas socioeconomicamente contrastantes localizadas próximas uma à outra.

Palavras-chave: Desigualdade socioeconômica. Segregação socioespacial. Configuração urbana. Sintaxe espacial. Índice socioeconômico.

\begin{abstract}
In this paper, the relationships between socioeconomic inequality and the location of different socioeconomic strata in Florianopolis' Conurbation Area (ACF) was examined. A multi-dimensional Socioeconomic Index based on the 2010 Brazilian Census data was beuilt and contrasted it with configurational properties of the grid using the Theory of Space Syntax and its main measures. Several recurring patterns were identified, both at the global and local levels. Results show that more privileged groups tend to occupy areas that are highly accessible. Despite higher global Choice averages, upper cohorts tend to avoid locating themselves directly on main streets or highways, preferring, instead, a
\end{abstract}

BCK é arquiteta e urbanista e mestre em Arquitetura e Urbanismo, e-mail: brunakron@gmail.com

RTS é arquiteto e urbanista e doutor em Engenharia Civil, e-mail: renato.saboya@ufsc.br 
more inwards oriented location in relation to the foreground network. That seems to express a strategy which balances relative isolation with easy access to the city center. On the other hand, lower cohorts are more often located along these streets, at least when they have characteristics of highways. At the local level, grid discontinuities and the prevention of mutual visibility are the main strategies used to separate two socioeconomic contrasting areas that, otherwise, are located near each other.

Keywords: Socioeconomic inequality. Sociospatial segregation. Space syntax. Urban configuration. Socioeconomic index.

\section{Introdução}

O desenvolvimento do Brasil urbano foi profundamente influenciado pelas contradições da cidade (Freyre, 2014): a riqueza e a pobreza, a classe dominante e as camadas populares, os sobrados e os mocambos, os condomínios fechados e as favelas. De acordo com Villaça (2012, p. 44), "o maior problema do Brasil não é a pobreza, mas a desigualdade e a injustiça a ela associadas". Compreender a sociedade brasileira implica, portanto, compreender o fenômeno urbano da desigualdade socioeconômica. Da mesma forma, compreender o espaço urbano brasileiro - palco de contradições e disputas de classe, bem como elemento ativo nesse processo - implica compreender a segregação socioespacial.

Algumas compreensões da sociedade e do espaço urbano e, consequentemente, da desigualdade socioeconômica e da segregação socioespacial abordam o tema a partir da visão clássica de círculos concêntricos - ou centro/periferia. Essa perspectiva ganhou força no início do século XX, com a Escola de Chicago, e continua a repercutir em diversos estudos socioespaciais. Entretanto, a descrição generalizada do espaço e a desconsideração das relações socioeconômicas da sociedade (Harvey, 1980), bem como de suas materializações no território, direcionam a uma compreensão ideológica dos fenômenos urbanos, tomando as injustiças sociais, por exemplo, a segregação socioespacial, como fenômenos "naturais" ou inevitáveis (Gottdiener, 1997).

Em contrapartida, a perspectiva do espaço urbano enquanto produção social permitiu inserir sua compreensão na lógica do materialismo histórico, da dominação e do conflito de classes (Villaça, 2012). Nesse cenário, a segregação socioespacial passa a ser compreendida como o resultado da disputa por localização no espaço urbano entre agentes com grandes assimetrias de poder e de capacidade de aplicação de recursos. Consequentemente, entre as principais características que definem esse fenômeno urbano estão a localização e a distribuição desigual dos investimentos no espaço urbano (Sugai, 2015).

A segregação socioespacial não significa necessariamente uma ocupação homogênea, mas uma concentração de determinados grupos sociais em uma região mais que em qualquer outra da cidade (Villaça, 2001). Dessa forma, esse fenômeno urbano caracteriza-se como um processo por meio do qual as camadas de mais alta renda tendem a se aglomerar em uma mesma direção do espaço urbano, concentrando os investimentos e, com isso, facilitando a dominação socioeconômica e política por meio do espaço (Villaça, 2001). Entre os resultados, estão as diversas cidades dentro de uma, com conexões bastante precárias ao longo de todo seu tecido urbano (Santos, 2012).

Nesse sentido, uma leitura do espaço capaz de descrevê-lo e considerá-lo em sua complexidade, sem as simplificações advindas de descrições generalistas da forma urbana ("anéis concêntricos" etc.) ou as limitações inerentes à linguagem verbal ("próximo", "distante", "segregado" etc.), torna-se essencial. Incorporam-se, portanto, ao estudo desse fenômeno aspectos da configuração espacial que permitem descrever e compreender as localizações dentro do espaço urbano de uma maneira mais refinada, revelando em diferentes escalas espaciais as possibilidades - e as probabilidades - de encontros entre diferentes grupos nos seus deslocamentos diários e na vida cotidiana. A análise configuracional auxilia a evidenciar sistemas de permeabilidades e barreiras ao movimento - e, portanto, proximidades e distâncias - entre localizações espaciais de uma forma mais precisa que as descrições tradicionais. Assim, enquanto alguns estudos sobre segregação socioespacial consideram o espaço urbano a partir de 
um espectro mais amplo e superficial, a análise configuracional descortina mais detalhes sobre ele, considerando a forma como o tecido está conectado.

A partir dessa perspectiva, esta pesquisa busca compreender a relação entre a desigualdade socioeconômica e a localização das diversas camadas da população na Área Conurbada de Florianópolis (ACF), investigando sua distribuição e a configuração do tecido urbano. Para tanto, caracteriza-se a ACF a partir da construção de um índice socioeconômico e descreve-se a configuração urbana por meio de duas das principais medidas da Teoria da Sintaxe Espacial: Integração e Escolha.

\section{Sintaxe espacial}

Desenvolvida durante a década de 1970 em Londres, a Teoria da Sintaxe Espacial defende a existência de uma lógica social do espaço e de uma lógica espacial da sociedade. A Sintaxe tem por objeto de estudo a configuração espacial (Bafna, 2003), entendida como a forma de articulação entre os elementos do espaço (Medeiros, 2013). Para a Sintaxe, a configuração espacial apresenta-se capaz de revelar relações hierárquicas existentes (Bafna, 2003), na medida em que diferentes espaços possuem distintas condições em relação ao resto do sistema (mais próximas ou mais distantes, mais na passagem ou fora dela, e assim por diante). Dessa forma, a configuração da malha viária pode ser um fator importante na definição dos fluxos, revelando características capazes de promover ou restringir o movimento de pedestres e de veículos, como, de fato, foi encontrado empiricamente em uma grande quantidade de trabalhos (Hillier et al., 1993; Penn et al., 1998; Hillier \& Iida, 2005).

A partir da abstração do espaço, a teoria desenvolveu algumas técnicas para a análise da configuração espacial, entre elas o Mapa Axial, que resulta de uma matriz de interseções de linhas axiais, entendidas como as maiores linhas retas capazes de cobrir todo o sistema de espaços convexos (Hillier \& Hanson, 1984). Assim, o Mapa Axial se caracteriza como a representação linear da configuração urbana (Figura 1). Estudos mais recentes, realizados a partir da década de 2000, começaram a utilizar uma nova unidade espacial em substituição à linha axial: o segmento, entendido como um ou mais segmentos de reta contidos entre duas interseções.

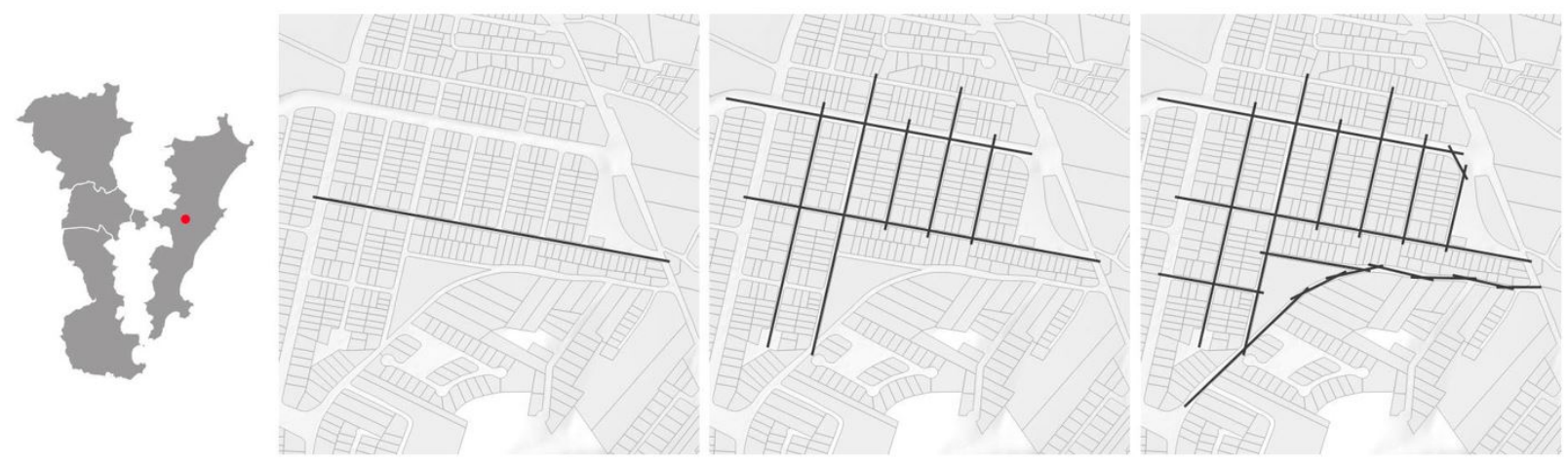

Figura 1 - Elaboração do Mapa Axial. Fonte: elaborada pelos autores.

Entre as medidas sintáticas utilizadas para analisar a configuração urbana, destacam-se a Integração e a Escolha. A medida de Integração diz respeito à maior ou à menor acessibilidade de um segmento do espaço urbano, tendo como referência o número mínimo de inflexões de percurso entre um ponto e outro (Holanda, 2010). Dessa forma, a Integração mede o quanto um segmento está próximo, em média, a todos os outros do sistema, e, portanto, sua maior ou menor probabilidade de ser o destino dos deslocamentos. A medida de Escolha, por sua vez, mede o quanto um segmento faz parte dos percursos entre todos os pares de segmentos do espaço urbano (Hillier et al., 2012; Hillier et al., 1987).

As medidas sintáticas podem ser analisadas na escala Global ou Local. A análise Global (Rn) considera todas as conexões a partir de todos os segmentos do sistema, com $\mathrm{R}$ representando o raio, $\mathrm{e}$ 
n, o número ilimitado de conexões (Medeiros, 2013). Quanto ao raio Local, para a análise de segmentos, considera-se uma distância de x metros em qualquer direção a partir de determinado segmento. Essa possibilidade de medir a Integração ou a Escolha de um segmento de rua em relação a diferentes raios é um dos grandes diferenciais desse tipo de análise, pois permite identificar papéis ou vocações, por exemplo, nas escalas da cidade, do bairro ou da vizinhança. Não é raro encontrar locais que possuem alta Escolha na escala Global, mas são mal conectados na escala Local, e, por isso, são usados como passagem entre bairros distantes, porém acabam não fazendo parte dos caminhos a pé feitos pelos moradores daquela vizinhança. 0 inverso também é comum: segmentos altamente conectados ao seu entorno imediato, desempenhando importante papel de centralidade local, mas fora das vias de passagem na escala da cidade. Essas diferenciações estão praticamente ausentes dos estudos tradicionais de segregação.

As medidas sintáticas podem ser extraídas numericamente, uma vez que cada segmento possui seu valor de Integração e de Escolha, e representadas no Mapa de Segmentos por meio de uma escala cromática com gradação do vermelho ao azul, passando ainda pelo laranja, amarelo e verde, na qual segmentos com maiores valores de Integração ou de Escolha tendem ao vermelho, e segmentos com menores valores, ao azul.

Desde a década de 1970, quando foram publicados os primeiros estudos, diversas pesquisas têm sido desenvolvidas no intuito de compreender a relação entre espaço e sociedade a partir da Sintaxe Espacial. Mais especificamente no que diz respeito à relação com a segregação socioespacial, Vaughan (2007) encontrou que, em Londres, no final do século XIX, as áreas ocupadas por população de baixa renda eram menos integradas que a média, com o oposto acontecendo nas áreas de alta renda.

No Brasil, Schroeder (2015) investigou a relação entre características configuracionais e a distribuição de renda sobre o espaço urbano de 29 cidades brasileiras de médio porte (200 mil a 350 mil habitantes). A pesquisa mostrou que, nessas cidades, a segregação socioespacial caracteriza-se pela localização das camadas de menor renda nas periferias, enquanto as de maior renda se concentram em áreas mais centrais, altamente integradas, com algumas exceções pontuais, como condomínios de alta renda na periferia, e concentração de alta renda em regiões específicas da cidade. Outros pontos foram evidenciados, como a presença de descontinuidades na malha viária separando os diferentes grupos econômicos, seja pela presença de vazios urbanos, seja por amplas avenidas que seccionam o tecido urbano.

Como qualquer teoria, a Sintaxe Espacial é uma simplificação da realidade e apresenta limitações. Medeiros (2013) propõe aceitar essas limitações e valorizar o que a diferencia de outras teorias: o âmbito relacional. A Sintaxe Espacial pode não revelar tudo sobre as cidades, mas é capaz de informar muito a respeito da lógica das práticas sociais que acontecem nelas (Holanda, 2013).

\section{Área Conurbada de Florianópolis (ACF)}

A Área Conurbada de Florianópolis (ACF) engloba quatro municípios (Florianópolis, São José, Palhoça e Biguaçu) em um contexto urbano brasileiro único: o patrimônio natural inestimável altamente atraente para turistas, e também base física para a produção e o consumo de seu espaço urbano -, a condição insular de significante parte de seu território e as profundas marcas no espaço e na cultura local provocadas pelos imigrantes açorianos.

Inicialmente, os principais focos de desenvolvimento concentraram-se em pequenas localidades em torno da Ilha de Santa Catarina, onde a pesca e a agricultura de subsistência foram as principais atividades econômicas. Os deslocamentos eram feitos quase exclusivamente pelo mar, com poucos e distantes caminhos terrestres sinuosos que conectavam as "freguesias", como eram conhecidas essas localidades (Reis, 2012). No entanto, em 1926, foi inaugurada a Ponte Hercílio Luz, marco da paisagem urbana de Florianópolis, que representou a substituição do transporte marítimo pelo rodoviário (Reis, 2012). Atualmente, duas pontes conectam a Ilha ao continente: a Ponte Governador Colombo Machado Salles (1975) e a Governador Pedro Ivo Campos (1991) - a Ponte Hercílio Luz encontra-se fechada para restauração. 
A partir de 1970, com a construção das rodovias federais BR-101 e BR-282, os quatro municípios experimentaram um expressivo incremento na fusão de seus tecidos urbanos, marcado, entre outros aspectos, pela concentração de investimentos públicos na porção insular - e mais rica (Sugai, 2015). Com a estrutura urbana praticamente consolidada na década de 1980, o sistema viário da área conurbada conformava-se por vias e rodovias da Ilha, em especial a Avenida Beira-Mar Norte e as SC401 e SC-404, que se conectavam à BR-282 e à BR-101, principais eixos viários do continente (Figura 2), formando "um eixo estruturador e de interligação entre as áreas de residências das elites e os bairros onde pretendiam expandir suas áreas residenciais e de veraneio" (Sugai, 2015, p. 148).

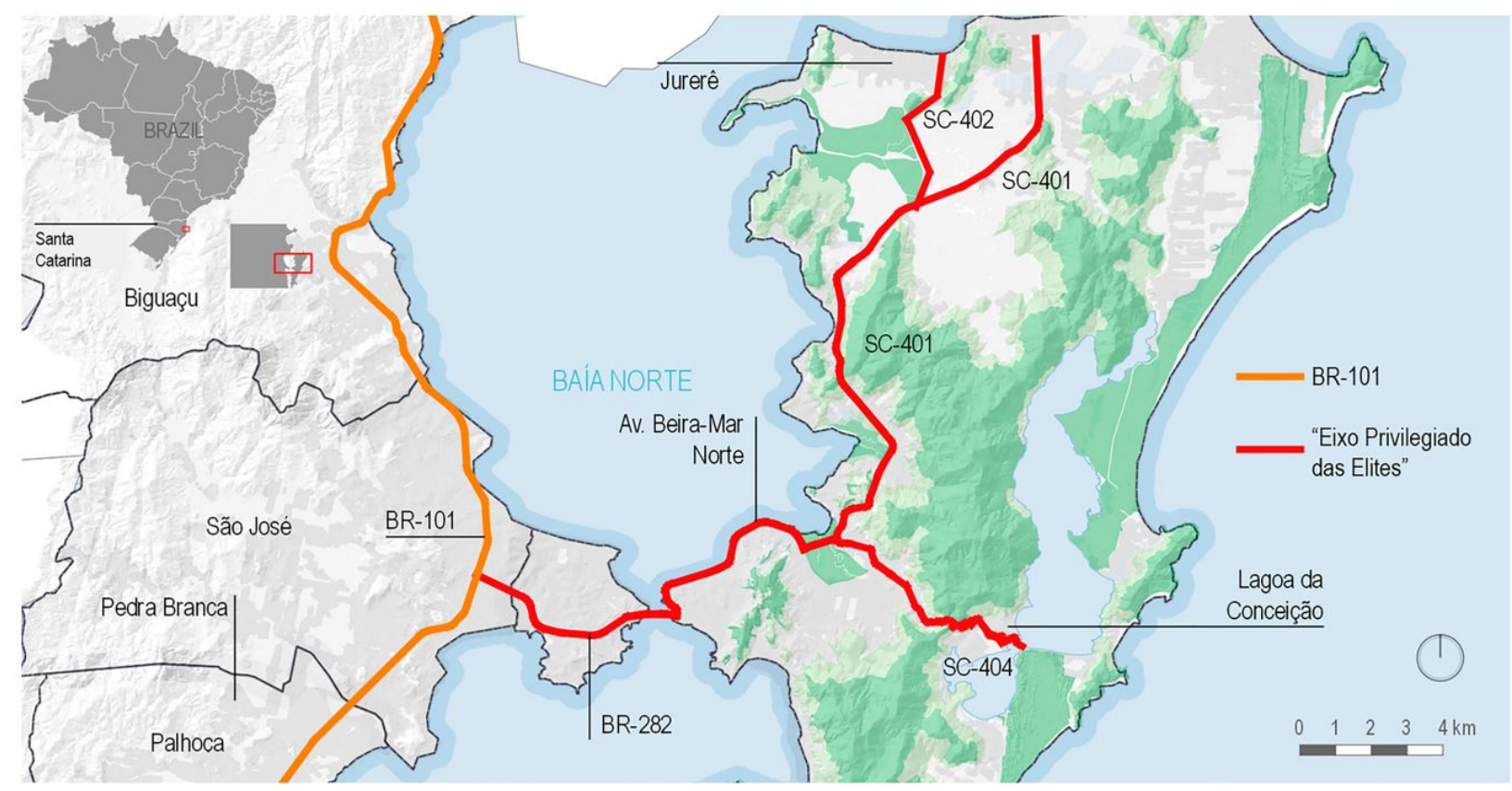

Figura 2 - Área Conurbada de Florianópolis e seus principais marcos geográficos e urbanos. Fonte: elaborada pelos autores com base nos dados da Prefeitura Municipal de Florianópolis (PMF).

Assim, a partir da década de 1980, foram observados o fortalecimento dos eixos da riqueza e a expansão da pobreza, o que se confirmou com a concentração das camadas de mais alta renda em Florianópolis e, principalmente, a concentração das elites na Ilha, integradas pelo sistema viário por meio desse "eixo privilegiado" (destacado em vermelho na Figura 2; Sugai 2015). A BR-282, que conecta as duas pontes à BR-101 e configura uma ruptura no tecido urbano continental de Florianópolis e de São José, proporcionou a continuidade desse eixo no continente, ampliando a acessibilidade e garantindo a conexão com outros bairros segregados das elites fora da Ilha. Essa ruptura resultou na divisão do território continental, no qual, na porção norte, concentraram-se as classes médias e as camadas mais populares, e na porção sul, as camadas de alta renda.

Esse eixo viário conectou os bairros das elites, desde o condomínio Bosque das Mansões no entroncamento entre a BR-101 e a BR-282, passando pelos bairros localizados ao sul da BR-282 (Bom Abrigo, Itaguaçu e Coqueiros), pela Via Contorno Norte-Ilha (Centro, Agronômica, Santa Mônica e Córrego Grande) e pelas SC-401 (Itacorubi, João Paulo, Cacupé, Canasvieiras, Praia Brava e Ingleses Norte), SC-402 (Jurerê Internacional) e SC-404 (Lagoa da Conceição) (Figura 3), o que confirma a tendência de concentração em uma mesma direção dos bairros segregados das camadas de maior renda também na ACF (Sugai, 2015; Villaça, 2001). 


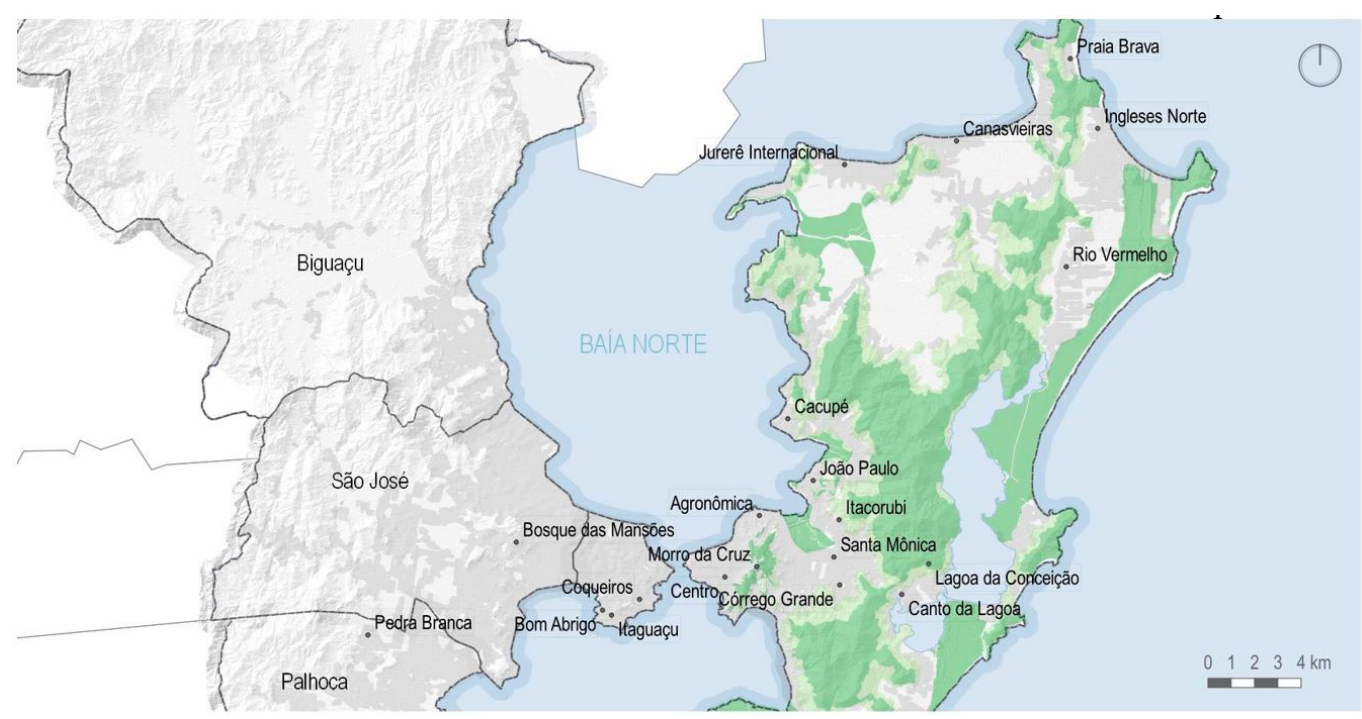

Figura 3 - Bairros e localidades de interesse na Área Conurbada de Florianópolis. Fonte: elaborada pelos autores com base nos dados da PMF.

Além desse eixo viário estruturante, Reis (2012) identifica duas formas principais de ocupação que se desenvolveram, principalmente, na Ilha: o parcelamento simples - marcado pelo traçado em espinha de peixe e pelas servidões, e que se desenvolveu ao longo dos caminhos coloniais e dos parcelamentos rurais preexistentes - e o parcelamento ordenado - configurado por uma malha ortogonal, presente em empreendimentos turísticos e de alta renda.

Durante a década de 1990, foi observado um aumento da riqueza em Florianópolis, com a ampliação das classes média e alta e a redução das camadas populares, o que não significou, no entanto, a redução das desigualdades socioeconômicas (Sugai, 2015). Ao contrário, estas foram reforçadas no período a partir da desigual distribuição dos investimentos públicos na área conurbada.

Quanto à localização e à distribuição de estabelecimentos comerciais, de ensino e de saúde na ACF (Figura 4), verificou-se uma leve concentração dos últimos na porção central da Ilha. Considerando que aproximadamente $60 \%$ da população dos municípios conurbados reside no continente, essa situação aponta para repercussões significativas na dinâmica desse espaço urbano, como deslocamentos diários em direção à Ilha por um único acesso - a Ponte Governador Pedro Ivo Campos -, enquanto a Ponte Governador Colombo Machado Salles direciona o fluxo no sentido contrário, em direção ao continente.
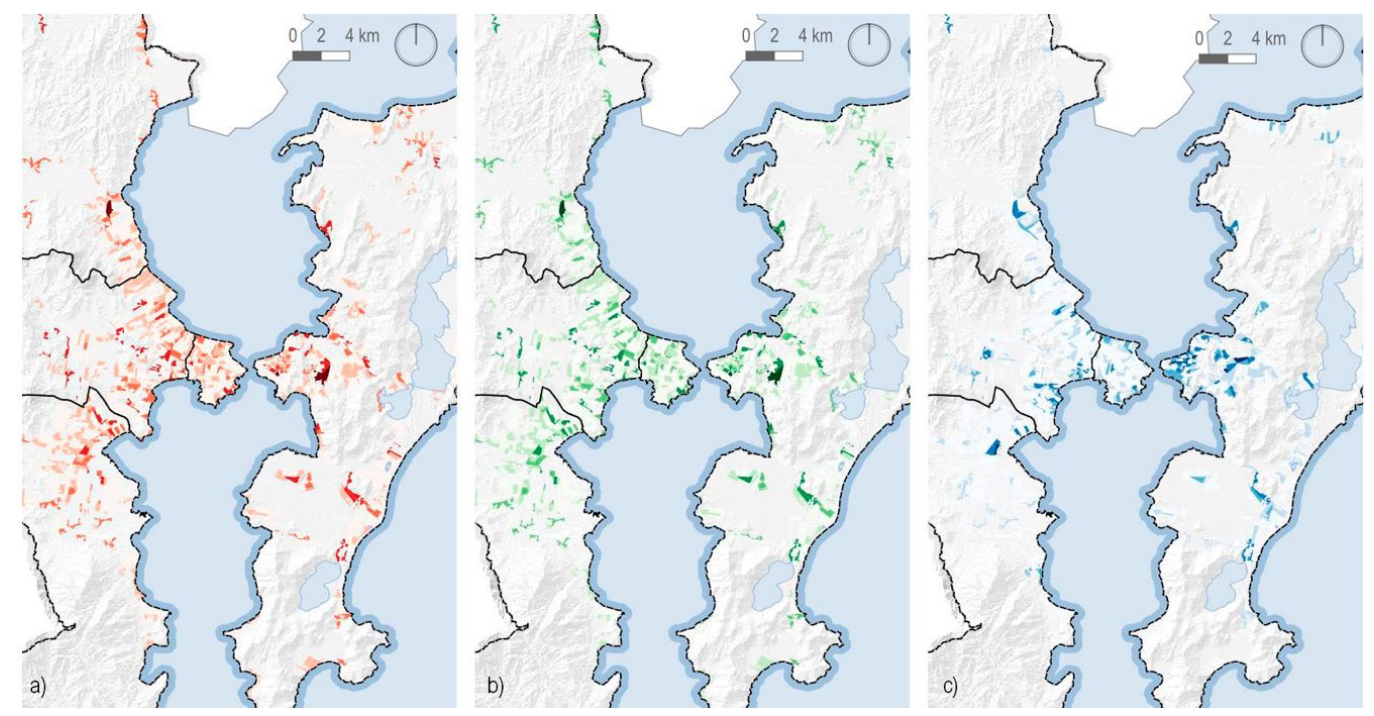

Figura 4 - a) Estabelecimentos comerciais; b) estabelecimentos de ensino; c) estabelecimentos de saúde. Fonte: elaborada pelos autores com base no CNEFE (IBGE, 2010). 
Percebe-se ainda a importância de observar a distribuição desses estabelecimentos de acordo com o porte e a capacidade de atendimento. Verificou-se, por exemplo, a localização de hospitais regionais e estabelecimentos de ensino de maior abrangência, como as universidades (UFSC, UDESC e Unisul) e o maior campus do Instituto Federal de Santa Catarina (IFSC), além de instituições públicas, como a Assembleia Legislativa (ALESC) - todos localizados na porção central da Ilha. Em contrapartida, serviços "indesejáveis", como o aterro sanitário, estão localizados distantes da capital, em Biguaçu.

Verificou-se, mais recentemente, o surgimento de condomínios fechados de alta renda na área continental com características de isolamento voluntário, enquanto empreendimentos habitacionais populares, como os do Programa Minha Casa Minha Vida, afastam-se do acesso à infraestrutura e aos equipamentos públicos involuntariamente (Sugai, 2015; Pereira, 2015).

\section{Método}

0 método articula dois objetivos específicos: a caracterização da realidade socioeconômica da ACF, a partir da construção do índice socioeconômico, e a caracterização da configuração urbana da ACF utilizando medidas da Sintaxe Espacial. A partir dos produtos dessas caracterizações, comparou-se a localização das diversas camadas socioeconômicas da população e suas características configuracionais.

\section{Caracterização socioeconômica}

O índice socioeconômico, baseado no trabalho de Jannuzzi (2012), utiliza os dados da Pesquisa Universo do Censo Demográfico 2010 do Instituto Brasileiro de Geografia e Estatística (IBGE), o que significa que a unidade territorial adotada é o setor censitário. A sua construção buscou algumas características-chave desejáveis, como confiabilidade, cobertura, inteligibilidade, factibilidade para obtenção dos dados, periodicidade na atualização e desagregabilidade geográfica.

0 índice tem a finalidade de caracterizar a população da ACF e sua distribuição no espaço urbano. A partir da temática, foram definidas as dimensões, ou as possíveis formas de interpretação ou de abordagem, tornando-as passíveis de ser indicadas quantitativamente. As dimensões que compõem o índice são: renda, educação, habitação, infraestrutura e vizinhança. Cada uma delas foi descrita a partir de uma ou mais variáveis, de acordo com sua disponibilidade no Censo 2010 do IBGE e considerações sobre possíveis redundâncias (Kronenberger, 2016).

A dimensão renda é, certamente, a mais importante na configuração de um indicador socioeconômico, uma vez que, em um modo de produção caracterizado pela compra da mão de obra por meio dos salários, nenhuma medida pode ser mais indicativa dos estados de desigualdade socioeconômica que aquelas ligadas aos vencimentos recebidos pela população.

Quanto à dimensão educação, esta precisa ser entendida como um mecanismo de reprodução social (Bourdieu \& Passeron, 2011), mantenedora dos estados de desigualdade, principalmente pelo acesso restrito aos seus graus superiores, outorgadores dos diplomas que conferem capital cultural (Bourdieu \& Passeron, 2011) ao seu portador. Ao mesmo tempo, a educação se configura, dialeticamente, como o mais importante elemento de mobilidade social para as classes populares, de tal modo que continua verdadeira a máxima de Paulo Freire: "Se a educação sozinha não transforma a sociedade, sem ela, tampouco, a sociedade muda" (Freire, 2000, p.31). Dentro dessa dualidade reprodução/transformação, a dimensão educação é de importância fundamental para a composição de um índice socioeconômico.

As condições da habitação também constituem um importante indicador da situação socioeconômica da população, uma vez que são capazes de influenciar, direta ou indiretamente, a qualidade de vida dos seus moradores (Ribeiro \& Ribeiro, 2013). Condições precárias de habitação relacionam-se com riscos à saúde e ao ambiente, e a sua alta incidência pode ser indicativa de condições de vida também precárias.

No que se refere aos indicadores da dimensão infraestrutura, é preciso alertar que, ao contrário do que ocorria em décadas passadas, atualmente o abastecimento de água e a disponibilidade de energia elétrica tendem a ser serviços universalizados. Dessa forma, esses indicadores de atendimento, antes 
suficientes para retratar diferenças sociais, têm se tornado obsoletos, tendo reduzida a sua relevância para a caracterização da população de diversos municípios brasileiros (CEBRAP, 2004).

A dimensão vizinhança, por sua vez, está intimamente ligada à infraestrutura e, para os efeitos deste estudo, diferencia-se por procurar evidenciar a ação do Poder Público na constituição do espaço urbano que caracteriza o setor censitário, sem se aprofundar no âmbito do domicílio. Assim sendo, apesar das dificuldades dessa dimensão para evidenciar desigualdades entre os estratos socioeconômicos médio e alto da sociedade, são extremamente eficientes para destacar a pobreza.

Com a definição das dimensões e de suas variáveis, foram levantados os valores referentes a cada variável e prosseguiu-se a normalização deles, definindo a escala de 0 a 1 , na qual valores próximos a 0 indicam setores em piores condições socioeconômicas, enquanto valores próximos a 1 indicam melhores condições. Essa normalização significa que o índice capta o contexto socioeconômico relativo à ACF, e não os valores absolutos.

A determinação dos pesos de cada dimensão e de suas respectivas variáveis foi feita utilizando o método Analytic Hierarchy Process (AHP), desenvolvido por Thomas L. Saaty, sendo um método multicritério amplamente utilizado e mundialmente reconhecido. A sua aplicação consiste em comparações par a par de cada elemento considerado (Tabela 1) utilizando a "Escala de Saaty” (Quadro 1).

Tabela 1 - Matriz AHP para a composição do índice socioeconômico

\begin{tabular}{cccccc}
\hline & Renda & Educação & Habitação & Infraestrutura & Vizinhança \\
\hline Renda & 1 & 4 & 3 & 4 & 5 \\
Educação & $1 / 4$ & 1 & $1 / 2$ & 2 & 3 \\
Habitação & $1 / 3$ & 2 & 1 & 2 & 3 \\
Infraestrutura & $1 / 4$ & $1 / 2$ & $1 / 2$ & $1 / 3$ & 3 \\
Vizinhança & $1 / 5$ & $1 / 3$ & $1 / 3$ & 1 \\
\hline
\end{tabular}

Fonte: elaborada pelos autores.

Quadro 1 - Escala fundamental de Saaty

\begin{tabular}{|c|c|c|}
\hline $\mathbf{1}$ & Igual importância & As duas dimensões contribuem igualmente para a temática. \\
\hline $\mathbf{3}$ & $\begin{array}{c}\text { Importância pequena de uma } \\
\text { sobre a outra }\end{array}$ & $\begin{array}{c}\text { A experiência e o julgamento favorecem levemente uma } \\
\text { dimensão em relação à outra. }\end{array}$ \\
\hline $\mathbf{5}$ & $\begin{array}{c}\text { Importância grande ou essencial } \\
\text { dimensão em relação à outra. }\end{array}$ & $\begin{array}{c}\text { A experiência e o julgamento favorecemte uma } \\
\text { dimertem relação à }\end{array}$ \\
\hline $\mathbf{7}$ & Importância muito grande & $\begin{array}{c}\text { Uma dimensão é muito fortemente favorecida em outra, e sua dominação de importância é demonstrada na } \\
\text { prática. }\end{array}$ \\
\hline $\mathbf{2 , 4 , 6 , 8}$ & Importância absoluta & $\begin{array}{c}\text { A evidência favorece uma dimensão em relação à outra com o } \\
\text { mais alto grau de certeza. }\end{array}$ \\
\hline
\end{tabular}

Fonte: adaptado de Saaty (1990).

Essa comparação semântica entre as dimensões permite a obtenção de uma matriz numérica que expressa quantitativamente a importância de cada dimensão em relação a todas as outras, considerando o contexto urbano em análise. Cada célula da Tabela 1 pode ser interpretada como a importância relativa da dimensão contida na linha sobre a dimensão contida na coluna. A importância atribuída a cada comparação par a par também está relacionada à qualidade ou à limitação de determinada variável em representar o fenômeno.

Partindo da Matriz AHP (Tabela 1) e com o auxílio do software PriEst, chegou-se à modelagem matemática do índice socioeconômico, com os pesos para cada dimensão e suas respectivas variáveis apresentados na Tabela 2. 
Tabela 2 - Dimensões, variáveis e pesos do índice socioeconômico

\begin{tabular}{|c|c|}
\hline Dimensões e variáveis & Peso \\
\hline Renda & 0,482 \\
\hline $\begin{array}{l}\text { - Rendimento mensal dos domicílios particulares permanentes em número de cestas } \\
\text { básicas }\end{array}$ & 0,75 \\
\hline - $\quad$ Pessoas responsáveis com rendimento nominal mensal de até 2 salários mínimos & 0,25 \\
\hline Educação & 0,146 \\
\hline - Pessoas responsáveis alfabetizadas & \\
\hline Habiłação & 0,198 \\
\hline - Banheiros por morador & \\
\hline Infraestrutura & 0,111 \\
\hline $\begin{array}{l}\text { - Proporção de moradores em domicílios particulares permanentes com banheiro de uso } \\
\text { exclusivo dos moradores ou sanitário e esgotamento sanitário via rede geral de esgoto ou } \\
\text { pluvial }\end{array}$ & 0,731 \\
\hline $\begin{array}{l}\text { - } \quad \text { Proporção de moradores em domicílios particulares permanentes com lixo coletado por } \\
\text { serviço de limpeza }\end{array}$ & 0,081 \\
\hline $\begin{array}{l}\text { - Proporção de moradores em domicílios particulares permanentes com energia elétrica } \\
\text { de companhia distribuidora }\end{array}$ & 0,188 \\
\hline Vizinhança & 0,063 \\
\hline $\begin{array}{l}\text { - Proporção de moradores em domicílios particulares permanentes próprios (existe } \\
\text { iluminação pública) }\end{array}$ & 0,074 \\
\hline $\begin{array}{l}\text { - Proporção de moradores em domicílios particulares permanentes próprios (existe } \\
\text { pavimentação) }\end{array}$ & 0,549 \\
\hline $\begin{array}{l}\text { - Proporção de moradores em domicílios particulares permanentes (não existe esgoto a } \\
\text { céu aberto) }\end{array}$ & 0,248 \\
\hline $\begin{array}{l}\text { - Proporção de moradores em domicílios particulares permanentes (não existe lixo } \\
\text { acumulado nos logradouros) }\end{array}$ & 0,129 \\
\hline
\end{tabular}

Fonte: elaborada pelos autores.

Considerando os coeficientes obtidos a partir do $A H P$, acredita-se que a modelagem matemática do índice corresponde às formulações teóricas apresentadas, reconhecendo a predominância da dimensão renda para a caracterização das desigualdades socioeconômicas, sem descuidar, no entanto, da observação sobre outras características que configuram uma situação de precariedade.

0 índice, considerando a disponibilidade de informações do Censo IBGE 2010, pode possuir algumas limitações caso seja usado para observar diferenciações entre os estratos socioeconômicos mais altos. Sua modelagem matemática, contudo, é concebida para realçar as distinções entre os estratos socioeconômicos mais altos e os mais baixos, destacando as condições de maior desigualdade.

A partir do índice final, foram estabelecidas cinco faixas, divididas em intervalos iguais, indo desde a faixa $\mathrm{A}$, para os valores mais altos, até a faixa E, para os valores mais baixos. Em linhas gerais, setores da faixa A são aqueles que possuem maior rendimento mensal por domicílio, pouco ou nenhum chefe de família ganhando menos de 2 salários mínimos mensalmente, maior número de chefes de família alfabetizados, casas com melhores condições de infraestrutura e bairros com serviços urbanos, enquanto setores da faixa E apresentam condições opostas. As demais faixas representam situações intermediárias. 


\section{Caracterização configuracional}

A caracterização configuracional do espaço urbano da ACF foi feita por meio de uma análise angular de segmentos, consistindo em Integração Global (Rn), Integração Local (R1200m - equivalente a uma caminhada de 15 minutos), Escolha Global (Rn) e Escolha Local (R1200m), utilizando o software Depthmap.

Depois de levantar as informações socioeconômicas e configuracionais da ACF, os valores foram exportados para um software de geoprocessamento (QGIS), permitindo a sobreposição das informações e o processamento das análises visuais e estatísticas.

\section{Resultados}

\section{Caracterização socioeconômica}

A partir da distribuição dos estratos socioeconômicos no espaço urbano da ACF, notou-se a localização dos estratos mais altos em Florianópolis, principalmente na Ilha, em detrimento dos outros municípios - São José, Palhoça e Biguaçu. Verificou-se ainda a concentração da faixa A ao longo do direcionamento que Sugai (2015) chamou de "eixo privilegiado das elites", no qual se destacam setores localizados ao sul da BR-282, ao longo da Avenida Beira-Mar Norte, em direção ao norte até Jurerê Internacional, e a leste em direção à Lagoa da Conceição (Figura 5).

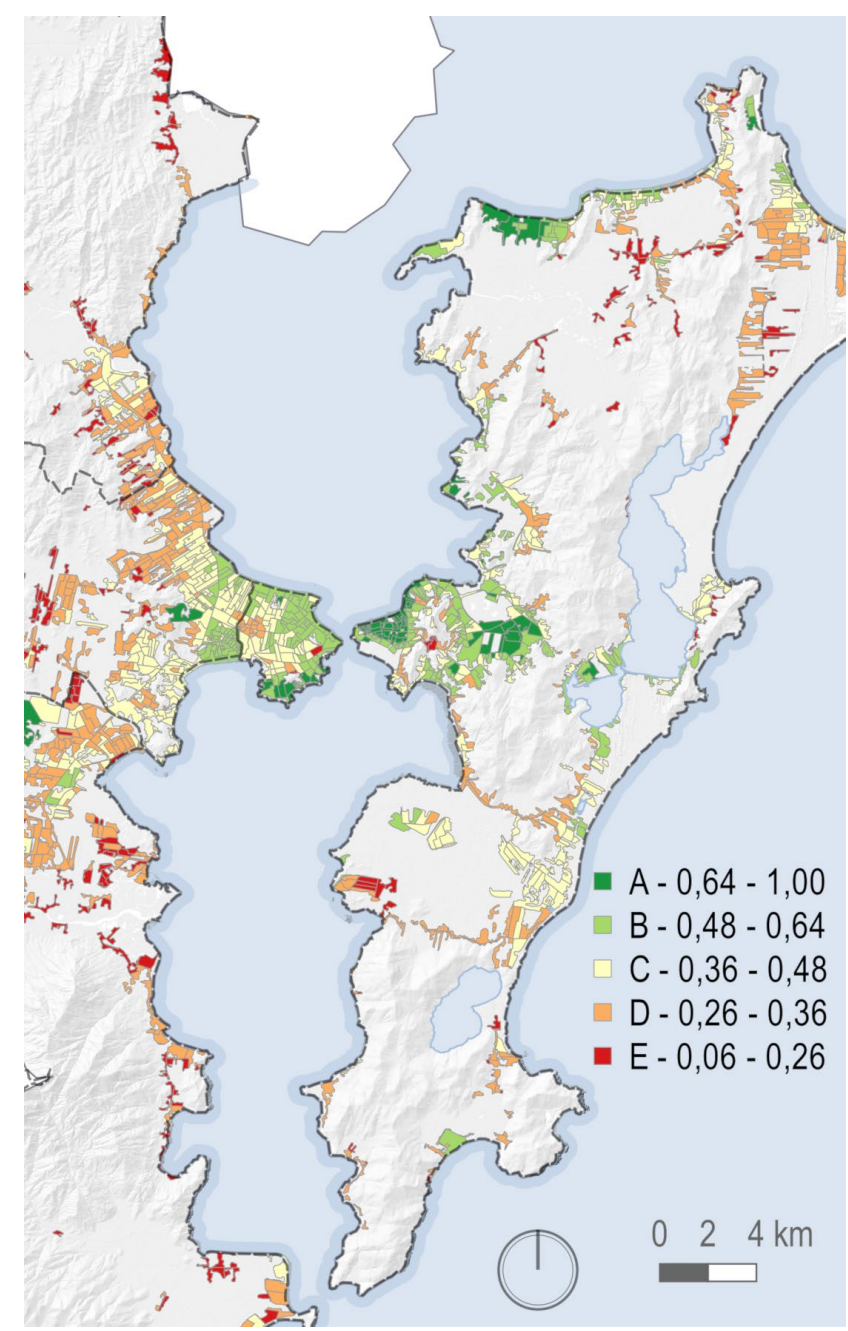

Figura 5 - Índice socioeconômico. Fonte: elaborada pelos autores. 
Quanto aos estratos socioeconômicos opostos, notou-se a localização de setores com piores condições socioeconômicas nas periferias do espaço urbano conurbado, principalmente no continente, e nas regiões nordeste e sul/sudeste da Ilha. Chama a atenção ainda a situação socioeconômica dos setores localizados no município de Biguaçu, quase todos classificados nas faixas D e E. Por outro lado, foram vistos também alguns desses estratos localizados em áreas centrais, ainda que em número significativamente menor.

\section{Caracterização configuracional}

No que diz respeito à análise configuracional, notou-se uma ocupação urbana mais concentrada nas porções centrais insular e continental, nas quais estão localizados os segmentos mais integrados (Figura 6b). Fora desse núcleo de integração, observou-se um tecido urbano consideravelmente mais disperso, resultando em vários bairros desconectados nas periferias. Isso é consequência de três fatores principais: condições ambientais extremamente complexas e variadas, prévia estruturação fundiária rural e substituição de uma estrutura urbana baseada em fluxos navais por outra fundamentada em um sistema viário bastante precário (Saboya et al., 2016).
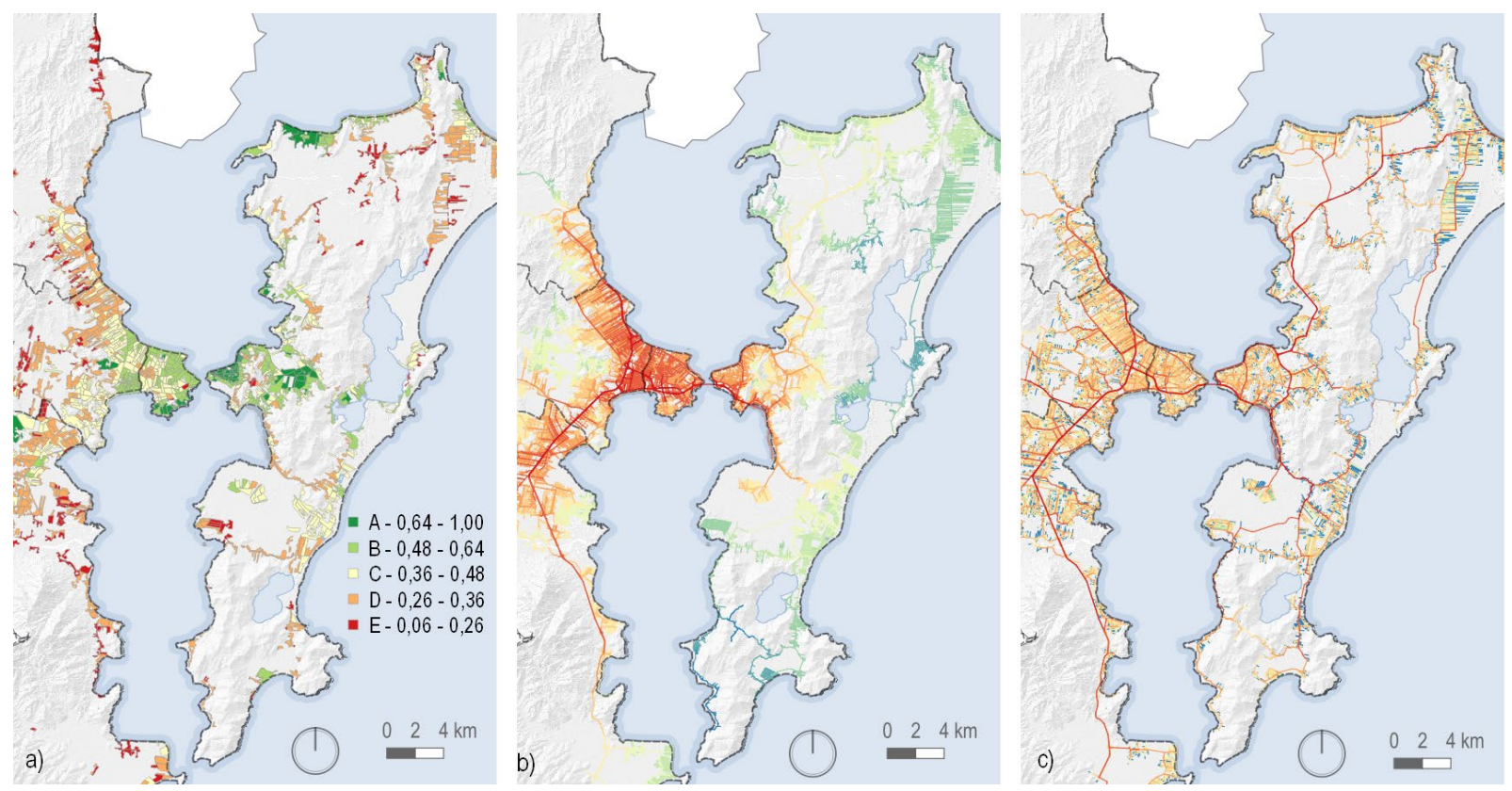

Figura 6 - a) Índice socioeconômico; b) Integração Global (Rn); c) Escolha Global (Rn). Fonte: elaborada pelos autores.

A Escolha Global (Figura 6c) evidencia uma rede primária que estrutura as localidades, constituída, principalmente, por rodovias que dividem - mais do que integram - o tecido urbano. Devido a uma estrutura próxima de árvore, várias dessas rodovias são as únicas conexões existentes entre importantes localidades. No continente, entretanto, há maior ocorrência de situações em que a rede primária está mais próxima da rede secundária, facilitando o acesso da primeira a partir da segunda e, portanto, oferecendo maior variedade de percursos possíveis. 


\section{Análise socioespacial: escala global}

\section{Classes privilegiadas em vias mais integradas globalmente}

A partir da sobreposição do índice socioeconômico à Integração Global (Rn), fica clara a proximidade de setores com melhores condições socioeconômicas a vias mais integradas. Isso ocorre na maior parte dos casos, ainda que alguns desses setores estejam localizados fora do núcleo de integração, caso de Jurerê e Lagoa da Conceição, ao norte e a leste da Ilha, respectivamente, e Pedra Branca, no oeste de Palhoça. Desses casos, apenas o último não está relacionado a uma amenidade ambiental (praia e lagoa para os dois primeiros, respectivamente).

A Figura 7 confirma essa tendência e mostra que há uma pequena queda nos valores de Integração Global (Rn) para a faixa E. As Figuras 7c e 7d evidenciam com mais detalhes as localizações da faixa A em comparação com a faixa $E$, também confirmando que faixas com melhores condições socioeconômicas estão localizadas em áreas mais integradas. Isso sugere que classes privilegiadas tendem a ocupar áreas da cidade mais próximas, em média, do sistema como um todo, revelando um desejo (e capacidade) de se apropriar das melhores regiões em termos de acessibilidade. Ao mesmo tempo, no entanto, essas classes parecem evitar as vias mais integradas de todas, provavelmente por causa do incômodo supostamente associado a um maior número de pessoas e à vitalidade desses espaços, preferindo vias um pouco menos (ainda que altamente) integradas.
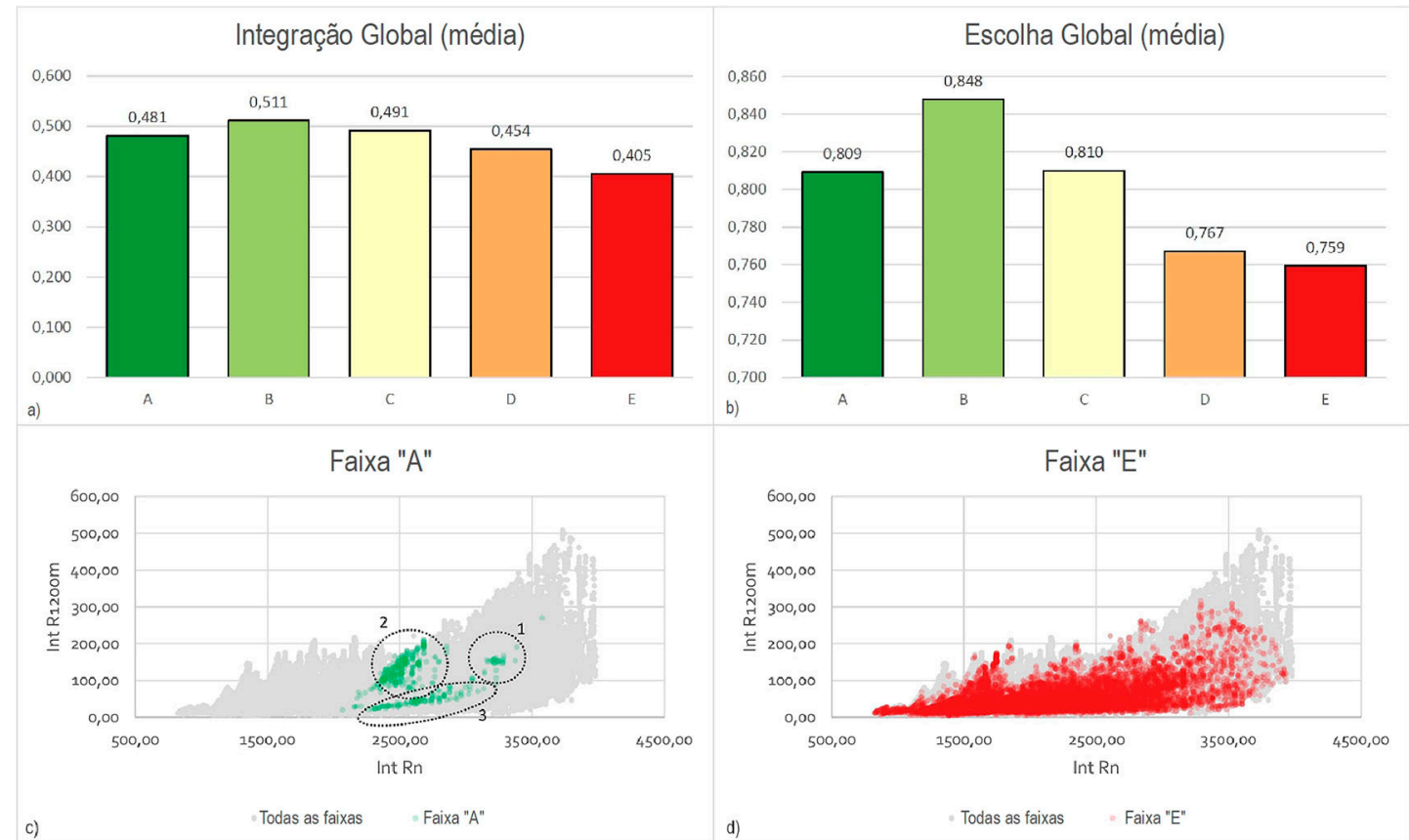

Figura 7 - a) Médias de Integração Global normalizadas para as faixas socioeconômicas; b) médias de Escolha Global normalizadas para as faixas socioeconômicas; c) gráfico de dispersão da faixa A (não normalizado); d) gráfico de dispersão da faixa E (não normalizado). Fonte: elaborada pelos autores.

A Figura 7c mostra que a Integração Global $(\mathrm{Rn})$ média da faixa $\mathrm{A}$ é alcançada pela combinação de valores médio-altos em um intervalo relativamente pequeno, especialmente se comparado à faixa $\mathrm{E}$ (Figura 7d). Também evidencia três clusters distintos: o primeiro (1), Beira-Mar Norte, é uma área ao longo do mar com alta Integração Global (Rn) e média-alta Integração Local (R1200); o segundo (2) corresponde aos bairros planejados com média Integração Global (Rn) e média-alta Integração Local (R1200) (Jurerê, Pedra Branca e Jardim Anchieta), que representam empreendimentos mais recentes que evitaram as áreas mais centrais e apresentam escassas conexões com o entorno imediato; o terceiro 
cluster (3) compreende, em sua maior parte, bairros associados a amenidades ambientais (Praia Brava, Canto da Lagoa da Conceição e Cacupé). Uma exceção a ser considerada, uma vez que não está próxima a nenhuma amenidade ambiental importante, é o Bosque das Mansões, na parte central de São José. Todos os locais do cluster 3 estão mal conectados no nível local, apresentando características de comunidades fechadas (ou sendo efetivamente, como o Bosque das Mansões) e estruturas internas semelhantes à de árvore, enquanto variam mais livremente nos valores de Integração Global (Rn).

Da mesma forma, fica claro que a grande maioria dos setores da faixa E (Figura 7d) está localizada em áreas mais segregadas, periféricas e desconectadas, como pode ser visto a partir da comparação entre as Figuras $7 \mathrm{a}$ e $7 \mathrm{~b}$. Embora existam setores dessa faixa em regiões mais integradas, o que caracteriza claramente exceções, e não a regra, essas situações provavelmente foram originadas a partir da combinação de ocupações irregulares e necessidade de proximidade aos locais de emprego e aos equipamentos públicos. As análises numéricas apresentadas nas Figuras $7 \mathrm{a}$ e $7 \mathrm{~b}$ confirmam esse cenário, ainda que a Figura $7 \mathrm{~d}$ mostre uma variedade de localizações da faixa E muito maior e uma abrangência de quase toda a gama de Integração Global (Rn). No entanto, a imagem não deixa dúvida de que existe uma concentração significativamente maior de localizações nos intervalos de valores médio-baixos.

\section{Atividades não residenciais em faixas intermediárias}

Como esperado, há certa coincidência entre a Integração Global (Rn) e a densidade de atividades não residenciais e empregos (Figura 6b e Figuras 8b e 8c). A Figura 8 mostra, no entanto, que maiores densidades de atividades não residenciais quase nunca são encontradas nas faixas extremas do índice socioeconômico, concentrando-se muito claramente em torno de 0,5-0,6 (Figura 9).

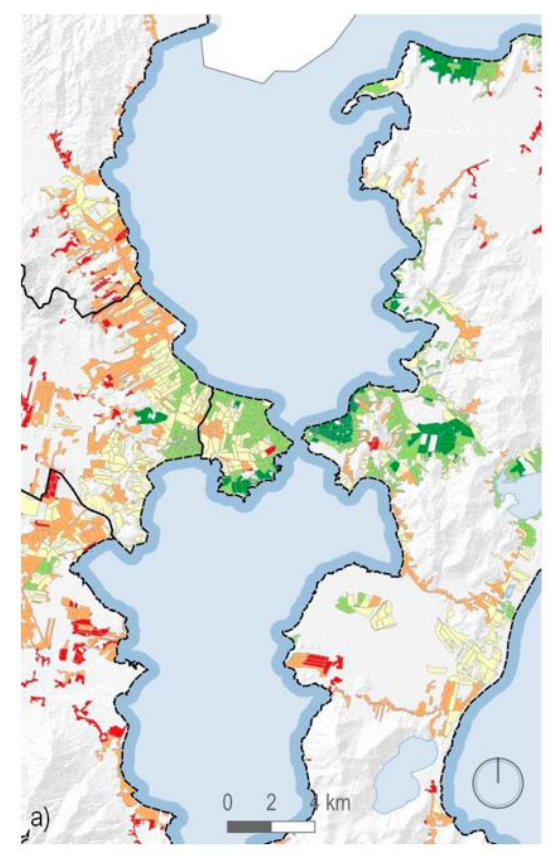

Figura 8 - a) Índice socioeconômico; b) densidade de usos não residencial; c) quantidade de empregos. Fonte: elaborada pelos autores. 


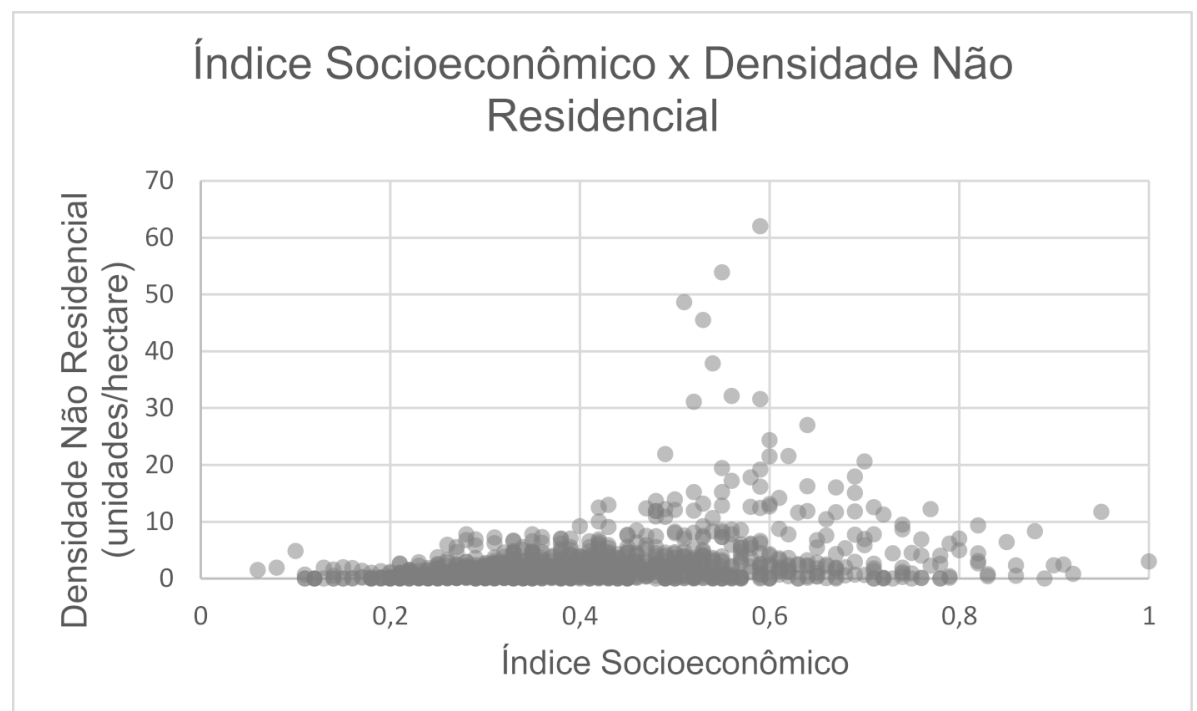

Figura 9 - Densidade de uso não residencial e índice socioeconômico. Fonte: elaborada pelos autores.

Nesse sentido, a densidade de atividades não residenciais diminui em ambas as direções. Talvez isso corrobore a tentativa de evitar as vias mais integradas pela faixa mais alta, como mencionado anteriormente. Atividades não residenciais são, afinal, fontes de movimento de pessoas e veículos, sons, trânsito de ônibus e caminhões, cheiros e outros inconvenientes. Além disso, esse grupo socioeconômico tem ampla mobilidade e disposição para trocar acessibilidade (proximidade) por um ambiente mais silencioso. Isso, em conjunto com a proximidade de vias com altos valores de Escolha Global (Rn), como será visto, garante uma ótima localização dentro do espaço urbano.

Em resumo, tem-se uma situação em que há uma alta dependência entre os quatro municípios e a área central principal, com condições especialmente ruins no caso da faixa E, que está localizada em regiões mais distantes da conurbação. Essas regiões são extremamente mal atendidas por atividades não residenciais - não apenas comércio, mas importantes equipamentos públicos, como terminais de ônibus, hospitais, órgãos do governo, entre outros. Como consequência, a privação socioeconômica é ainda pior devido a essa combinação de aspectos de localização, especialmente quando são consideradas a necessidade de acesso a essas atividades em locais longe de casa e a dependência de um sistema de transporte público deficiente.

\section{Classes privilegiadas próximas a vias com alta Escolha Global (Rn), mas não muito próximas}

As diferenças dos valores de Escolha Global (Rn) entre as diferentes faixas são ainda mais pronunciadas do que no caso da Integração Global (Rn) (Figura 6). Em média, os valores de Escolha Global (Rn) da faixa A são consideravelmente maiores, sugerindo localizações próximas ou nas próprias vias com grande quantidade de "movimento através". Essa proximidade, entretanto, não significa contato direto; em várias regiões, o que acontece é que a faixa A está próxima a rodovias com altos valores de Escolha Global (Rn), mas ligeiramente afastada delas. Isso facilita o acesso à rodovia (e, consequentemente, ao centro), ao mesmo tempo que evita o incômodo provocado pelo tráfego intenso.

Por outro lado, as faixas D e E, com frequência, ocupam áreas imediatamente adjacentes a vias com alta Escolha Global (Rn), o que pode ser verificado em vários locais, como a rodovia SC-401 (Figura 10-1), que conecta o centro às praias ao norte; o Distrito do Rio Vermelho, a nordeste (Figura 10-2); as rodovias BR-101 (Figura 10-3) e BR-282 (Figura 10-4); e a rodovia SC-405 (Figura 10-5). Isso ocorre, no entanto, quando a rodovia apresenta caraterísticas de via expressa, mas não quando apresenta qualidades ambientais e turísticas, como a Avenida Beira-Mar Norte. Da mesma forma, em localizações que combinam altos valores 
de Escolha Global (Rn) e de Integração Global (Rn), existem mais setores da faixa C e menos da faixa E ao longo da rodovia (comparando a porção sul da BR-101 com sua porção central, por exemplo).

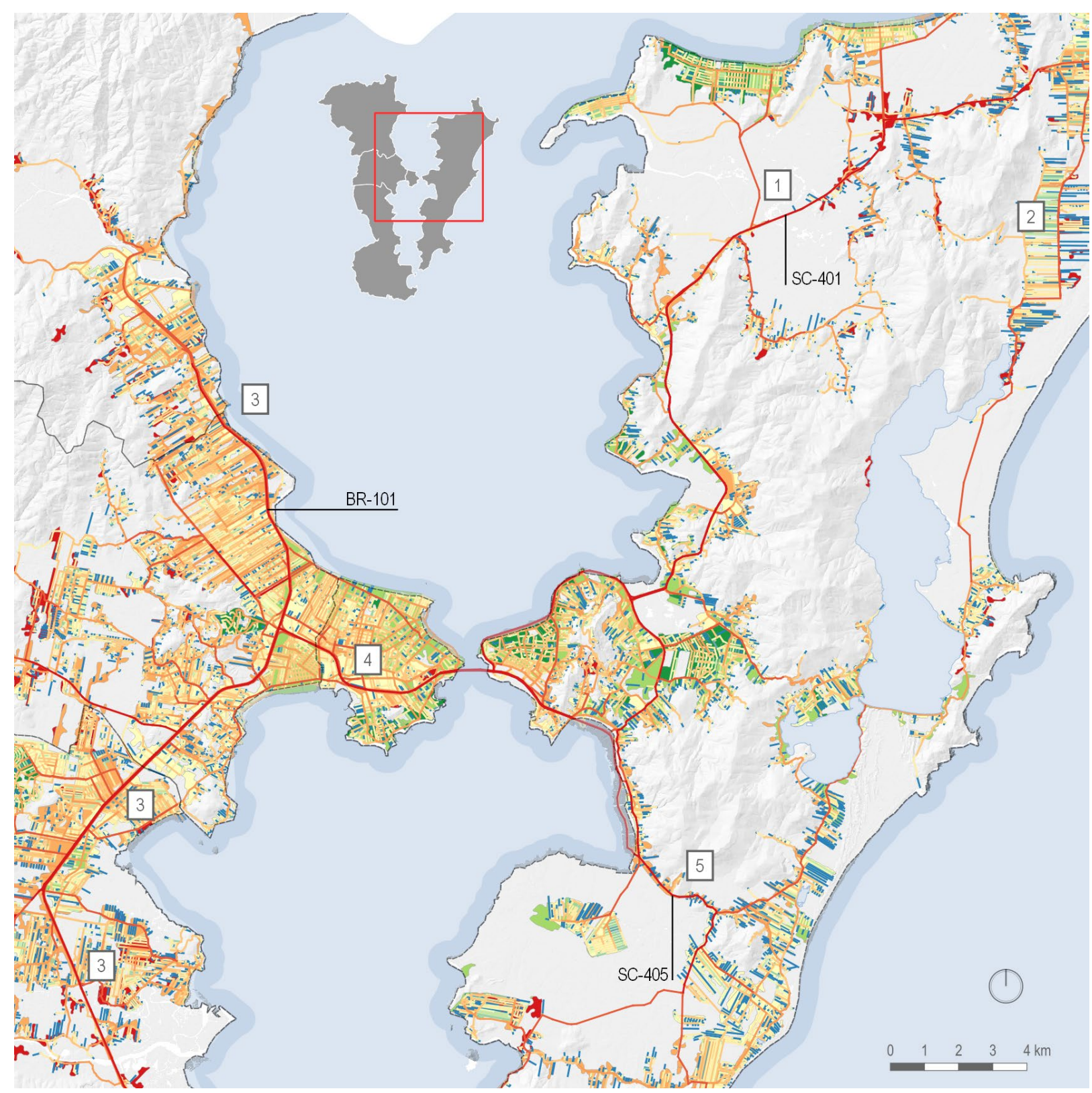

Figura 10 - Faixas C e E nas rodovias de alta Escolha: 1) SC-401; 2) Rio Vermelho; 3) BR-101; 4) BR-282; 5) SC-405. Fonte: elaborada pelos autores.

Essa combinação de altos valores (mas não os mais altos) de Integração e Escolha Global (Rn) pode ser considerada uma descrição mais precisa daquilo que Sugai (2015) chamou de "eixo privilegiado das elites". Oferece às classes socioeconômicas mais altas dois tipos de vantagem de localização: permanecem, em média, mais próximas ao resto do sistema e mais próximas, mas não diretamente adjacentes, a vias que contêm importantes conexões com o tecido urbano e estão no caminho entre outras localizações. Isso, por sua vez, está vinculado à presença de atividades comerciais e vitalidade microeconômica (Hillier, 2009). Ao mesmo tempo, são capazes de evitar externalidade negativas associadas a esses fatores.

É notável que uma medida puramente configuracional seja capaz de capturar um fenômeno tão claramente. Mostra o poder dos investimentos na transformação da estrutura material da cidade, 
especialmente quando são comparados os caminhos coloniais originais com os percursos contemporâneos mais linearizados. A minimização da distância angular, ou seja, da quantidade e intensidade de mudanças de direção ao longo dos percursos, parece ter sido uma força ativa e significante nessa transformação ao longo das décadas.

\section{Análise socioespacial: escala local}

\section{Faixas com piores condições socioeconômicas em vias com baixos valores de Escolha e Integração Local (RI200)}

Assim como na escala Global, foram verificadas faixas com piores condições socioeconômicas localizadas em vias com baixos valores de Escolha e de Integração Local (R1200), embora provavelmente por diferentes motivos (Figura 11). Enquanto no caso global os baixos valores das faixas D e E estão relacionados a baixos preços de localizações distantes das áreas mais integradas, na escala Local esse não é necessariamente o caso, uma vez que não há razões óbvias para assumir que conjuntos de vias localmente integradas têm valores mais elevados de terra que conjuntos de vias localmente mais segregadas.

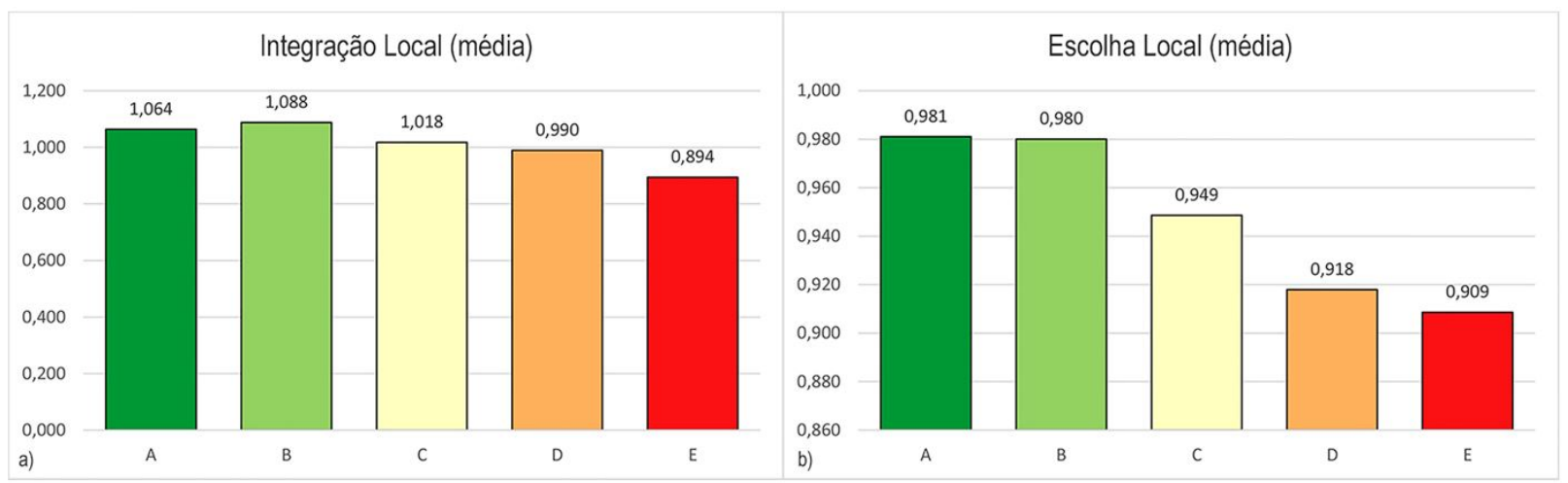

Figura 11 - Médias de a) Integração Local e b) Escolha Local, normalizadas pelas faixas socioeconômicas. Fonte: elaborada pelos autores.

Não foi possível identificar inequivocamente a causa do fenômeno, mas é provável que ele se deva à estrutura em árvore predominante na maioria das áreas periféricas, bem como à segregação e à baixa Escolha Local (R1200), que, quase por definição, caracterizam áreas nas porções mais externas de qualquer sistema sintático. Parece, entretanto, que os bairros planejados para classes mais altas, às vezes, conseguem contornar essa estrutura em árvore e alcançar sistemas viários quase em grelha.

Áreas altamente integradas localmente tendem a oferecer melhores condições de desenvolvimento de centralidades locais (Hillier, 1999, 2009), contato social e melhor uso dos equipamentos públicos em seus arredores, considerando que o raio de 1.200 metros equivale a uma caminhada de aproximadamente 15 minutos. A população mais desfavorecida, que vive em áreas localmente segregadas, tem essas possibilidades prejudicadas, acrescentando mais uma desvantagem espacial à sua já difícil situação.

\section{Segregação por descontinuidade do tecido urbano}

$\mathrm{Na}$ escala Local, verificou-se a segregação pela descontinuidade do tecido urbano entre áreas adjacentes com condições socioeconômicas contrastantes. Existem diversos exemplos em que os desalinhamentos entre as vias separam áreas que, de outro modo, estão muito próximas umas das 
outras. Esse é o caso, por exemplo, das áreas desfavorecidas no Morro da Cruz, na área central de Florianópolis e relativamente próximas à Beira-Mar Norte (Figura 12a); Pedra Branca e Frei Damião, no continente (Figura 12c); e Bosque das Mansões, um condomínio fechado (Figura 12e). As Figuras 12b, $12 \mathrm{~d}$ e $12 \mathrm{f}$ destacam os caminhos mais curtos entre as áreas socioeconomicamente contrastantes representadas nas imagens à esquerda. Torna-se claro que qualquer possibilidade de interação em padrões diários de movimento fica severamente restrita nessas situações.

De fato, há razões para acreditar que essa segregação gerada pelo tecido urbano pode ter importantes implicações no surgimento (ou na falta) de laços de vizinhança entre essas áreas adjacentes. Não apenas a circulação dos pedestres é prejudicada como também dos veículos motorizados. Além disso, mesmo as rotas do transporte coletivo têm que fazer voltas excessivas para cobrir uma área razoável. Como resultado, a copresença (e seus possíveis desdobramentos, como interação, familiaridade, colaboração, vínculos fracos e fortes etc.) entre pessoas de diferentes classes sociais e origens também é minimizada.

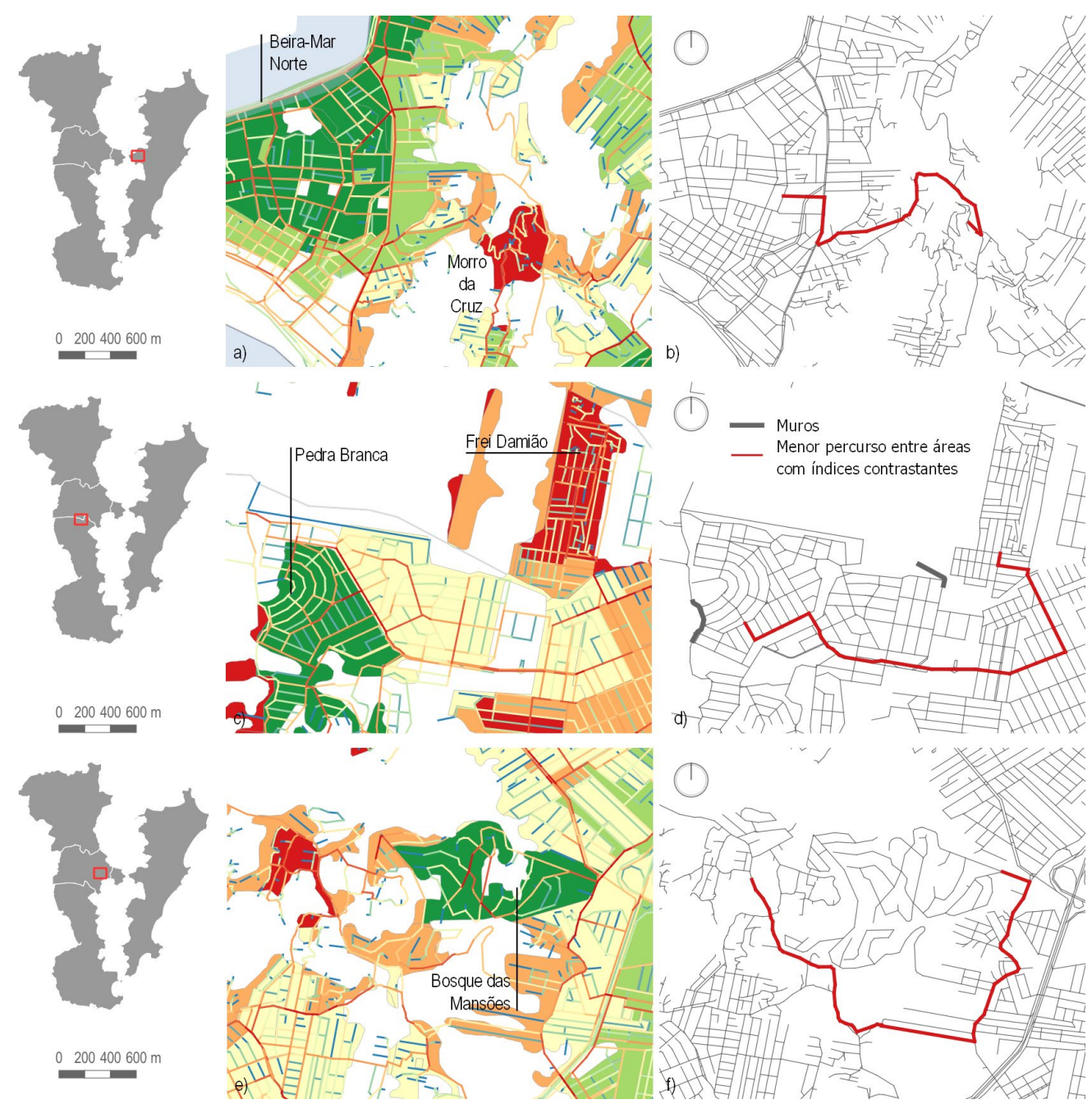

Figura 12 - a) Beira-Mar Norte e Morro da Cruz; b) menores percursos para (a); c) Pedra Branca e Frei Damião; d) menores percursos para (c); e) Bosque das Mansões; f) menores percursos para (e). Fonte: elaborada pelos autores.

Às vezes, mas não sempre, essa situação emerge como resultado (ao menos parcialmente) das condições topográficas, que têm o efeito de fazer desconexões mais "naturais" e, ao mesmo tempo, esconder uma comunidade da outra. Esse é o caso do Morro da Cruz e do Bosque das Mansões, mas não de Pedra Branca e Frei Damião. Os últimos, apesar de terem valores semelhantes de Integração Global (Rn), têm valores de Integração Local (R1200) bem diferentes. Pedra Branca tem uma avenida central 
(Avenida Pedra Branca) que atravessa toda a sua extensão, estrutura seu tecido urbano e é altamente integrada na escala Local. ${ }^{1}$ Possui a tendência de ser a semente de uma centralidade local que, no entanto, não é uma opção viável para os morados de Frei Damião. Aparentemente devido à ausência de um morro que separa as duas comunidades, um muro foi construído para garantir que nem mesmo a visibilidade mútua fosse possível, como pode ser visto nas Figuras $12 \mathrm{~d}$ e 13 . Outro muro foi construído ao longo da interface de outra comunidade privada a oeste. A localização e a extensão desses muros não deixam dúvidas quanto aos tipos de contato que estão tentando evitar.

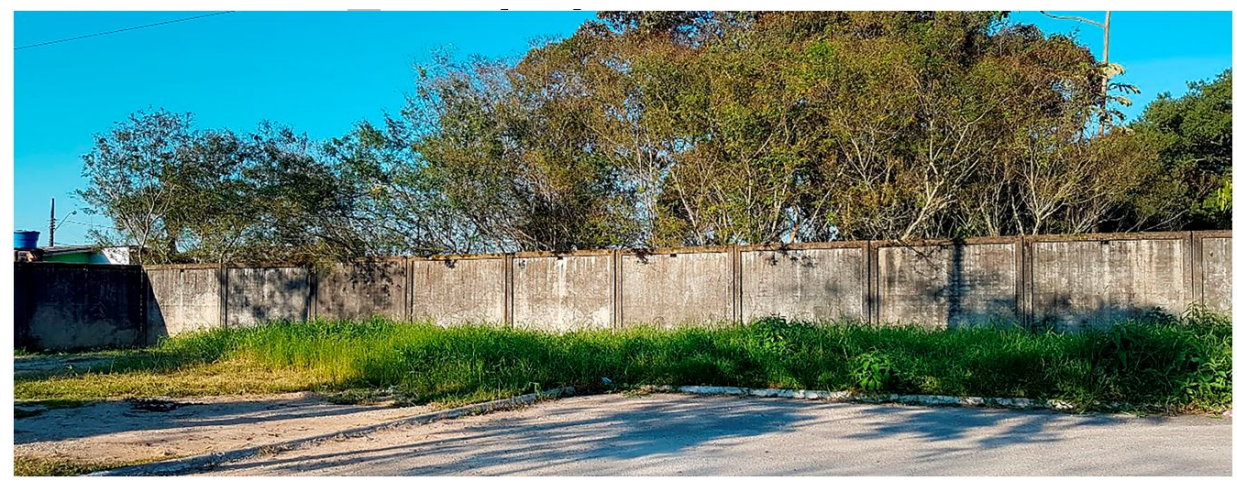

Figura 13 - Muro que separa Pedra Branca de Frei Damião. Fonte: elaborada pelos autores.

No caso da Beira-Mar Norte e do Morro da Cruz (Figura 14), apesar de estarem na área central da Ilha, possuem valores de Integração Global ( $\mathrm{Rn}$ ) bem diferentes (Figura 14a). A proximidade entre eles não foi capaz de superar os efeitos de um tecido urbano altamente desconectado e tortuoso que caracteriza a comunidade. Talvez mais preocupante seja a Integração Local (R1200), que também é muito baixa, obstruindo o surgimento de fortes espaços de encontro para seus habitantes e manutenção de atividades comerciais e comunitárias (Figura 14c).

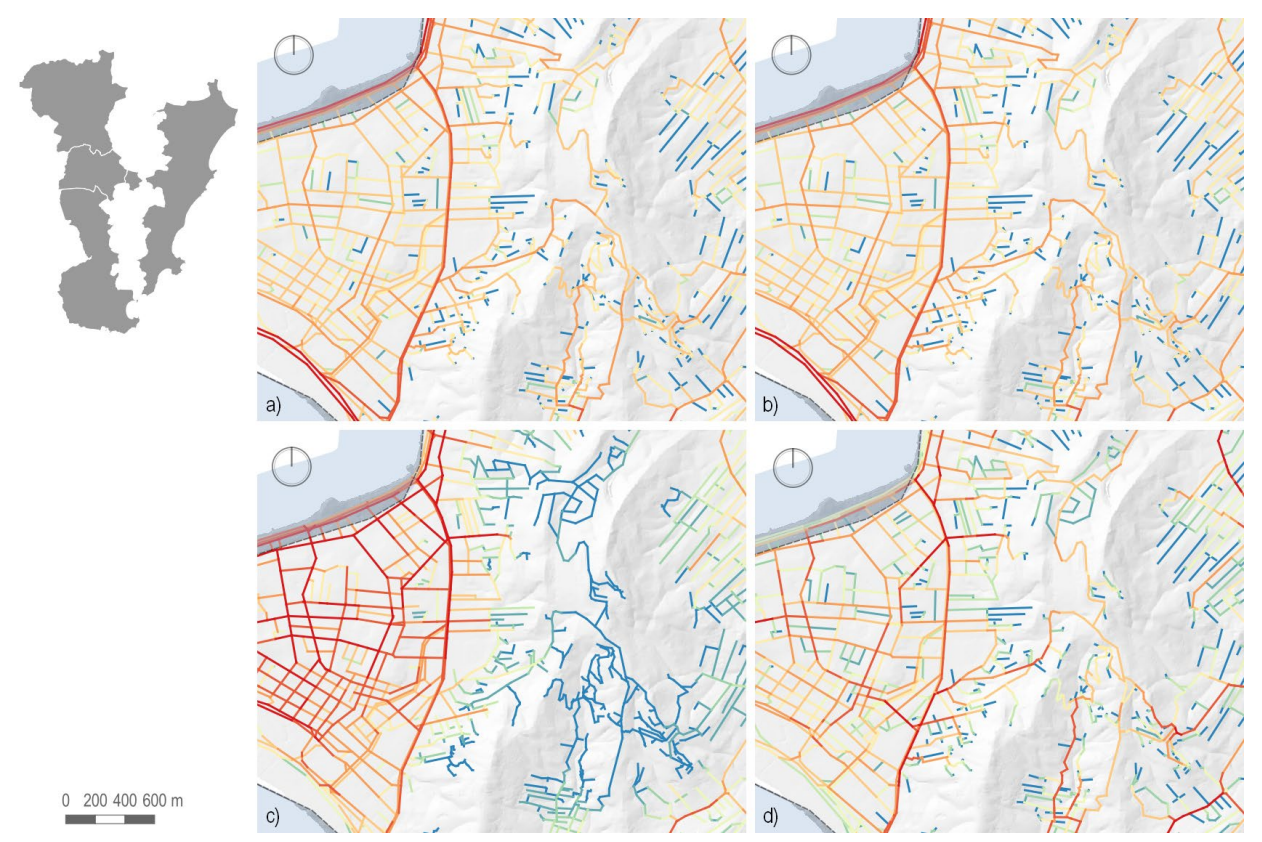

Figura 14 - a) Integração Global normalizada; b) Escolha Global normalizada; c) Integração Local (R1200) normalizada; d) Escolha Local (R1200) normalizada. Fonte: elaborada pelos autores.

\footnotetext{
${ }^{1}$ A porção amarela a leste da porção verde também faz parte da Pedra Branca. A classificação na faixa C seja provavelmente devido ao seu desenvolvimento mais recente e a imprecisões, nessa escala, dos setores censitários.
} 
Esta pesquisa buscou compreender a localização das diferentes faixas socioeconômicas da população na ACF, investigando a sua distribuição e a configuração do espaço urbano a partir da construção de um índice, de um lado, e de medidas sintáticas, de outro. A soma de outros olhares que não foram contemplados neste trabalho, como questões ambientais ou de valor da terra, pode contribuir para a compreensão do espaço e dos fenômenos urbanos. Nessa direção, futuros trabalhos podem ser desenvolvidos a partir dos resultados desta pesquisa, agregando outras categorias de análise.

\section{Conclusões}

A partir das medidas sintáticas da configuração espacial, verificou-se que faixas com melhores condições socioeconômicas procuram não apenas localizações próximas ao centro como também mais remotas, mas que possuem acesso direto e fácil ao centro por vias ou rodovias com altos valores de Escolha Global (Rn). Isso não significa, como o estudo revelou, que essas faixas se localizam diretamente nessas vias. Em vez disso, elas têm a tendência de se (auto)segregar, isolando-se ligeiramente da rede primária, mas garantindo fácil acesso a ela. Por outro lado, observou-se que faixas com piores condições socioeconômicas estão mais frequentemente localizadas ao longo dessas vias, ao menos quando possuem características de rodovias.

No nível local, quando faixas socioeconômicas contrastantes estão próximas, a topografia e o sistema viário são usualmente usados para desconectá-las umas das outras e, assim, diminuir a probabilidade de encontros casuais e copresença nas atividades e nos movimentos diários. A supressão da visibilidade mútua também está presente nesses casos, alcançada por condições topográficas e pela construção deliberada de muros que separam essas áreas.

A consequência desse cenário de desigualdade socioeconômica e segregação socioespacial é a redução dos contatos entre pessoas de diferentes origens sociais e urbanas, com o consequente efeito de redução da coexistência e da oportunidade de exercer tolerância, empatia e negociação em situações que envolvem características e valores sociais desconhecidos. Além disso, a segregação na escala Global restringe o acesso de grupos mais desfavorecidos a equipamentos, emprego e comércio. Isso traz um fardo extra para um grupo que já se encontra em posição desprivilegiada, impondo tempos e custos de deslocamentos mais altos, diminuindo o tempo livre e restringindo a capacidade de realizar atividades sociais e de lazer, especialmente se considerar, como a análise mostrou, que as áreas ocupadas por esses grupos tendem a possuir baixo nível de diversidade de usos do solo.

Um conhecimento mais refinado sobre esses comportamentos locacionais, como o que este trabalho se propõe a gerar, permite intervenções e instrumentos normativos mais adequados para lidar com esses aspectos. No Brasil, onde o tecido urbano ainda está em formação em um grande número de áreas, com novos loteamentos e vias isoladas sendo abertos a cada dia, ainda existe uma capacidade relativamente alta de influenciar a consolidação da rede de sistemas de circulação em uma direção que: a) fomente o contato e a interação entre os diferentes; b) crie condições para o surgimento de centralidades principais e locais em diversas escalas, viabilizando a implantação e a sobrevivência de comércios, serviços e equipamentos públicos de diferentes tamanhos e raios de abrangência, que, por sua vez, podem atuar como catalisadores de encontros entre populações de bairros distintos; e c) garanta diversidade de caminhos alternativos entre localizações, evitando a concentração excessiva de fluxos em poucas vias e colaborando para a minimização dos problemas de trânsito e uma melhor distribuição dos valores do solo.

Se considerar que o sistema viário é um dos elementos mais perenes e de difícil modificação do espaço urbano e, ao mesmo tempo, possui uma influência tão importante sobre a dinâmica intraurbana, fica clara a importância de estabelecer critérios cuidadosos para o desenho da configuração, tanto no que diz respeito à criação de novas partes do tecido quanto à necessidade de intervenções pontuais para reconectar partes do tecido atualmente desconectadas. Quanto mais tempo passar e mais consolidado estiver esse tecido, mais difícil será corrigir os rumos. 


\section{Agradecimentos}

O presente trabalho foi realizado com apoio da Coordenação de Aperfeiçoamento de Pessoal de Nível Superior - Brasil (CAPES).

\section{Referências}

Bafna, S. (2003). Space syntax: a brief introduction to its logic and analytical techniques. Environment and Behavior, 35(1), 17-29. http://dx.doi.org/10.1177/0013916502238863.

Bourdieu, S., \& Passeron, J. C. (2011). A reprodução: elementos para uma teoria do sistema de ensino. Petrópolis: Editora Vozes.

CEBRAP. (2004). Mapa de vulnerabilidade social da população da cidade de são paulo. São Paulo: CEBRAP.

Freire, P. (2000). Pedagogia da indignação - cartas pedagógicas e outros escritos. São Paulo: Editora UNESP.

Freyre, G. (2014). Sobrados e mucambos. São Paulo: Global Editora.

Gottdiener, M. (1997). A produção social do espaço urbano (2nd ed.). São Paulo: Edusp.

Harvey, D. (1980). A justiça social e a cidade (Antônio Corrêa da Silva, trad.). São Paulo: Editora Hucitec.

Hillier, B. (1999). Centrality as a process: accounting for attraction inequalities in deformed grids. Urban Design International, 4(3-4), 107-127. http://dx.doi.org/10.1057/udi.1999.19.

Hillier, B. (2009). Spatial sustainability in cities: organic patterns and sustainable forms. In Proceedings of the 7th International Space Syntax Symposium (K01:1-K01:20). Stockholm: KTH.

Hillier, B., \& Hanson, J. (1984). The social logic of space. Londres: Cambridge University Press. http://dx.doi.org/10.1017/CB09780511597237.

Hillier, B., \& Iida, S. (2005). Network effects and psychological effects: a theory of urban movement. In Proceedings of The International Conference on Spatial Information Theory (pp. 475-490). Ellicottsville: COSIT.

Hillier, B., Burdett, R., Peponis, J., \& Penn, A. (1987). Creating life: or, does architecture determine anything? Architecture \& Behavior, 3(3), 233-250.

Hillier, B., Penn, A., \& Grajewsku, T. (1993). Natural movement: or, configuration and attraction in urban pedestrian movement. Environment \& Planning B, 20(1), 29-66. http://dx.doi.org/10.1068/b200029.

Hillier, B., Yang, T., \& Turner, A. (2012). Normalizing least angle choice in Depthmap and how it opens up new perspectives on the global and local analysis of the city space. Journal of Space Syntax, 3, 155-193.

Holanda, F. H. (2010). Brasília - cidade moderna, cidade eterna. Brasília: FAU UnB.

Holanda, F. H. (2013). Dez mandamentos da arquitetura. Brasília: FRBH.

IBGE. (2010). Censo demográfico 2010. Rio de Janeiro: Instituto Brasileiro de Geografia e Estatística.

Jannuzzi, P. M. (2012). Indicadores sociais no Brasil (5. ed.). Campinas: Editora Alínea.

Kronenberger, B. C. (2016). Entre a servidão e a beira-mar: um estudo configuracional da segregação socioespacial na Área Conurbada de Florianópolis (Dissertação de Mestrado). Universidade Federal de Santa Catarina, Florianópolis.

Medeiros, V. (2013). Urbis Brasiliae: o labirinto das cidades brasileiras. Brasília: EdUnB.

Penn, A., Hillier, B., Banister, D., \& Xu, J.-P. (1998). Configurational modelling of urban movement networks. Environment and Planning. B, Planning \& Design, 25(1), 59-84. http://dx.doi.org/10.1068/b250059. 
Pereira, E. M. (2015). Indicadores de urbanidade como aprimoramento para o Programa Minha Casa Minha Vida. Florianópolis: Laboratório Cidade e Sociedade, UFSC.

Reis, A. F. (2012). Ilha de Santa Catarina: permanências e transformações. Florianópolis: Editora da UFSC.

Ribeiro, L. C. Q. \& Ribeiro, M. G. (2013). IBEU: índice de bem-estar urbano (1. ed.). Rio de Janeiro: Letra Capital.

Saaty, T. L. (1990). How to make a decision: the Analytic Hierarchy Process. European Journal of Operational Research, 48(1), 9-26. http://dx.doi.org/10.1016/0377-2217(90)90057-I.

Saboya, R., Reis, A., \& Bueno, A. (2016). Continuidades e descontinuidades urbanas à beira-mar: uma leitura morfológica e configuracional da área conurbada de Florianópolis. Oculum Ensaios, 13(1), 129-152. http://dx.doi.org/10.24220/2318-0919v13n1a2756.

Santos, M. (2012). Manual de geografia urbana (3. ed.). São Paulo: Editora da Universidade de São Paulo.

Schroeder, T. (2015). Características configuracionais da segregação socioespacial em cidades médias brasileiras (Dissertação de Mestrado). Universidade Federal de Santa Catarina, Florianópolis.

Sugai, M. I. (2015). Segregação silenciosa: investimentos públicos e dinâmica socioespacial na área conurbada de Florianópolis (1970-2000). Florianópolis: Editora da UFSC.

Vaughan, L. (2007). The spatial syntax of urban segregation. Progress in Planning, 67(3), 205-294.

http://dx.doi.org/10.1016/j.progress.2007.03.001.

Villaça, F. (2001). Espaço intraurbano no Brasil. São Paulo: Studio Nobel.

Villaça, F. (2012). Reflexões sobre as cidades brasileiras. São Paulo: Studio Nobel.

Editor: Rodrigo Firmino

Recebido: Dez. 08, 2017

Aprovado: Out. 13, 2018 